\title{
PERCEIVED CULTURE OF NETWORKED KNOWLEDGE HUBS
}

\author{
Mattila, Pauliina (2); van der Marel, Floris (1); Mikkonen, Maria (1) \\ 1: Aalto University; 2: Swinburne University of Technology
}

\begin{abstract}
While the construction of knowledge hubs has gained recent traction, little is known on how networked actors perceive their collective culture. Authors looked at the topic through a single case study, the Design Factory Global Network, a network of 24 autonomous yet connected hubs for passion-based cocreation in an educational setting. Data was collected via questionnaires, asking 1) to describe their Design Factory in three distinct, words, 2) explicate these with exemplary stories, and 3) express future development wishes. 98 stories and future wishes were shared by representatives from 15 Design Factories. Excerpts reflecting cultural levels (attitudes, norms, manifestations) were identified and made sense of by looking at which level of stakeholder relationship (internal, host, network, wider environment) they targeted. 78 attitudes, 114 norms and 95 manifestations were mentioned, mostly targeting the internal community and the host levels. Authors draw some practical implications for each of the identified level or relationship, contributing to the knowledge of the creation and development of such innovation hubs. In addition, further research directions are proposed.
\end{abstract}

Keywords: Design education, Organizational processes, Open innovation, Collaborative design, Knowledge hub

\section{Contact:}

Mikkonen, Maria Eveliina

Aalto University

Aalto Design Factory / School of Engineering

Finland

maria.mikkonen@aalto.fi

Cite this article: Mattila, P., van der Marel, F., Mikkonen, M. (2019) 'Perceived Culture of Networked Knowledge Hubs', in Proceedings of the 22nd International Conference on Engineering Design (ICED19), Delft, The Netherlands, 5-8 August 2019. DOI:10.1017/dsi.2019.239 


\section{INTRODUCTION}

The formation of innovation and knowledge hubs has been on the rise in the past decade. These types of hubs have emerged for example in business settings (Fiore \& Rosani, 2018), as living labs used for developing communities (Leminen et al., 2012), as well as knowledge hubs within or in proximity of universities and higher educational institutions (Youtie \& Shapira, 2008) - thus these terms are often used interchangeably. While each hub has a specific role and purpose within its own context, three core components of innovation labs typically include: a physical environment, resources and facilitation (Memon et al., 2018). Evers and Dieters (2008) describe knowledge hubs as meeting places for different knowledge and interest communities, where the core activities revolve around transfer of knowledge between the different participants. More specifically in a university context, a knowledge hub can be described as a "boundary-spanning organisation that accumulates mediating functions for the exchange of tacit as well as codified knowledge between academia and local business and financial communities" (Youtie \& Shapira, 2008, p. 1188).

While the construction of knowledge hubs has gained recent traction, little has been written on how the internal community perceives their own entities, as well as what the collective culture of networked actors is. One example of a network consisting of knowledge hubs within education and research institutions has been the Design Factory Global Network (DFGN). Identifying themselves as platforms for passion-based co-creation driving change in their local context, the first Design Factory was established at Aalto University in 2008 and has since then spread to 24 institutions across the world, creating a network of autonomous yet connected Design Factories. These entities bring together students, educators and academia with a larger community of businesses, government bodies and non-profits, to co-create and solve wicked problems. Each entity is based on similar values and ways of working, yet largely influenced by the local context i.e. surrounding society and culture, institution and design, business and engineering disciplines. Indeed, the DFGN can be viewed as a global knowledge ecosystem (Clarysse et al., 2014; Scaringella \& Radziwon, 2017) of networked hubs impacting their own local surroundings, as well as leveraging the knowledge of the network as a whole. What differentiates a knowledge ecosystem from an innovation ecosystem is that "the key activities are centered on the university and the dense network of surrounding companies" (Clarysse et al., 2014, p. 5).

As the DFGN network has expanded rapidly in recent years, a call for clarifying the common story and a collective identity was expressed by its members. With a knowledge ecosystem built on shared understanding and similar types of working methods, common identity and culture work is necessary for effective collaboration. Moreover, the need for communication on multiple levels such as within an organisation and externally to the wider environment is important for gaining legitimacy and demonstrating impact. If stories shared by a group of actors are consistent, there is likely to be more common understanding internally (Eriksson \& Kovalainen, 2015), as well as a stronger and more legit message to external audiences (Aldrich \& Ruef, 2006; Wry et al., 2011). Especially for the newer members of the network, narratives and stories about best practices from more experienced players can be useful, when they are yet to have many experiences of their own (Roundy, 2016).

The stories act as sense-making devices (Brown et al., 2008) to shape one's own understanding of the culture, manifested in different global locations and as a tool to share and influence external stakeholders (Brown, 1998). Therefore, we look at the stories through Schein's culture framework (1988) to help identify common cultural elements in all of the three cultural layers, as well as spot unique characteristics shaped by local factors; thus contributing towards the individual and collective identity formation of a global network of knowledge hubs. Through the analysis of how different critical incidents, turning points, successes and failures were told, especially in relation to other surrounding stakeholders, we expect to reveal the realities of developing and managing such innovative knowledge hub, especially within often conservative educational and research settings.

The main aim of this paper is to investigate how actors within an internal community perceive their own entities to contribute to current conversations of knowledge hubs and global networks of knowledge ecosystems. It does this by firstly identifying common cultural elements of knowledge hubs within educational and research institution settings and secondly shining light on how these stories are told in relation to different stakeholders; thus influencing the Design Factories' current and future ways of working. 


\section{METHODOLOGY}

\subsection{Data collection}

Given the open-ended and emergent nature of the phenomenon, a case study approach was chosen (Yin, 2009) as it allows to follow an open approach in order to understand complex social situations (Eisenhardt \& Graebner, 2007). The research approach was limited to a single case study as the aim was to understand the phenomenon within single settings (Eisenhardt, 1989) and the case itself is "particular" (Stake, 2005, p. 445). Single case study refers to one knowledge ecosystem, namely DFGN consisting of Design Factories; its network members. The primary source of data was a questionnaire with open-ended questions:

- My Design Factory:

- My role at our Design Factory:

- The 3 words I'd describe our Design Factory with are:

- Please write down an example, situation or practices that you do or have done at your Design Factory that somehow illustrates each of the three words you wrote down:

2. -

- What would you like to try next? What are you excited about moving forward?

Purposive sampling was used in order to reach the research goal by selecting the most productive sample (Marshall, 1996) and in order to collect a wide variety of perspectives (Maykyt \& Moorhouse, 1994). The questionnaire was distributed during an annual collective gathering of Design Factory representatives in June 2018 and handed out to those 56 participants representing 18 institutions. Participants' roles ranged from director positions to coaches, their time spent working at a Design Factory varied and the length of the membership in the network varied from recent joining to an established member institution with multiple years of experience.

The questionnaire consisted of three parts. First, participants were asked to describe their own institution with three distinctive keywords. The second part was a continuation of the first part where participants were asked to give examples, situations or practices illustrating each of the chosen words. The third part of the questionnaire tasked the participants to give examples of what they would like to do next and what excites them about moving forward. The questionnaire was distributed to all 56 participants, out of which 24 responses were received, resulting in a $43 \%$ response rate. Respondents represented 16 institutions, that is a number of representatives from each institutions varied from 1 to 3,9 institutions with 1 representative, 6 institutions with 2 representatives and 1 institution with 3 representatives. This resulted in 72 stories (3 distinct stories per respondent as per instructions in the questionnaire) and examples of institution culture as well as 24 future-related wishes.

\subsection{Data analysis}

Coding of the data was conducted in three phases. The first one was theory driven (top-down), using Schein's Three Levels of Culture framework (Schein, 1988). By no means do we claim this to be the only possible framework to make sense of the stories, nor do we claim respondents themselves to be aware of these levels, rather our framework supports us in exploring the perceived levels of culture reported by participants. An adaptation was made to better reflect the educational context and distinguishable elements present in the short written stories. 
Table 1. Adapted framework to make sense of the data

\begin{tabular}{|l|l|}
\hline Three Levels of Culture (Schein, 1988) & Our adapted framework \\
\hline $\begin{array}{l}\text { Level 1. Artifacts } \\
\text { Visible organizational structures and processes } \\
\text { (hard to decipher) }\end{array}$ & $\begin{array}{l}\text { Manifestations } \\
\text { Courses, programs, pressure cookers, physical } \\
\text { manifestations, e.g. maker spaces, concepting } \\
\text { spaces, open spaces, co-creation techniques,... }\end{array}$ \\
\hline $\begin{array}{l}\text { Level 2. Values } \\
\text { Strategies, goals, philosophies (espoused } \\
\text { justifications) }\end{array}$ & $\begin{array}{l}\text { Norms } \\
\text { Partnerships, community of practice, } \\
\text { interactions, collaborations, ... }\end{array}$ \\
\hline $\begin{array}{l}\text { Level 3. Assumptions } \\
\text { Unconscious, taken for granted beliefs, habits } \\
\text { of perception, thought and feeling (ultimate } \\
\text { source of values and action) }\end{array}$ & $\begin{array}{l}\text { Attitudes } \\
\text { Attitudes, drives, atmosphere, beliefs, ... }\end{array}$ \\
\hline
\end{tabular}

The thematic content of these stories on a semantic level (Braun \& Clarke, 2006) were mapped to the three levels: manifestations, norms and attitudes. All authors first went through the statements individually to identify sentences or parts of sentences expressing a certain manifestation, norm or attitude. As the authors are based at different Design Factories and have previously worked at and visited multiple Design Factories, as well as attended several International Design Factory Weeks, they were able to interpret stories within the context of that particular Design Factory. This allowed us to unravel the collective stories and see how underlying values and attitudes were linked with concrete manifestations and practices (Schein, 1988). A discussion was held to resolve any differences in coding and unsure cases until agreement was reached.

Second, a more bottom-up approach was used to group statements per level allowing meta-themes to emerge from the data. Through discussion, the authors agreed stories targeted one of the following four stakeholder relationships:

- Internal: targeting the community, mostly students and staff

- Host: targeting the connected institution, be it educational or research

- Network: targeting other Design Factories, or students and staff from other Design Factories

- External: targeting a wider environment, such as industry or society in general

All levels of culture from the adapted framework were represented in all different relations, resulting in twelve subgroups combining the levels of culture and the stakeholder relationships.

Third, within each subgroup excerpts were grouped and discussed by all authors to reveal patterns and themes. In this way, we were able to see how Design Factories were walking the talk, and thus concretizing their desirable impact in their everyday actions.

\section{RESULTS}

To enhance our understanding of how actors within DFGN, a global network of knowledge ecosystems, perceive their entity, members were asked to fill out questionnaires sharing stories that to them best described Design Factory. In total 26 participants from a total of 15 Design Factories returned the questionnaires. In total they shared 72 stories or examples describing their Design Factory culture and 26 future related wishes. Through the stories and future wishes, the respondent mentioned: 78 attitudes, 114 norms and 95 manifestations, reflecting what they believed to describe their Design Factory. The distribution of these levels per type of relation can be found in Figure 1. 


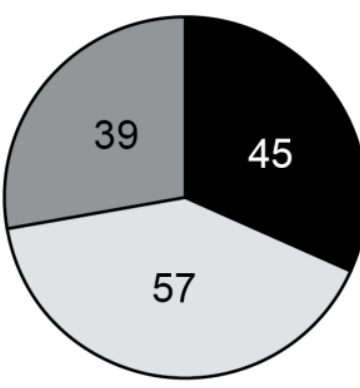

internal

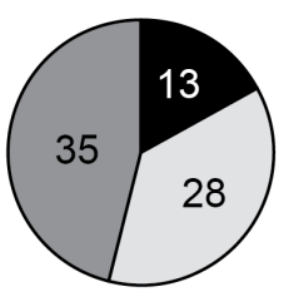

host

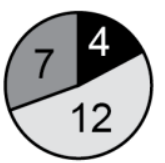

network

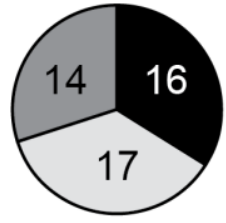

external norms

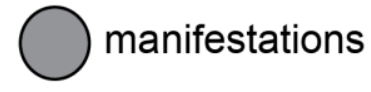

Figure 1. Distribution of excerpts in relation to levels of culture and relation to entity

\subsection{Internal}

Many stories contained elements reflecting on the internal community of the Design Factory (141 out of 287 identified expressions in total). Underlying attitudes were mentioned in 45 excerpts, supported by 57 norms or ways of working, explicated through 39 concrete manifestations.

On an attitudinal level the most identified theme was that of being an inclusive community (mentioned 15 times in the stories), supported by norms that promoted being helpful (mentioned 8 times) and close or informal with one another irrespective of their position or background (8), manifested in social rituals to promote bonding (9) and inviting people into the space and the community (3).

"In the beginning of the year [...] we give every new student access card, a [...] shirt and a hug to show them that we are a family and this is their second home. It was like the Olympics where we gave the card as a prize and believe it set the right atmosphere for the week."

The second most mentioned attitude related to a state of continuous adaptive development (8), combined with being goal-oriented (1) and successful (1), as was also reflected in norms focusing on growing by building a community, adapting to changes, training staff, organizing activities and developing ideas, norms which altogether were mentioned 13 times, two of which were future plans. Manifestations related to growth and development were not mentioned much as they were mostly seen as organic, only few shared future plans to develop a growth strategy (3).

"We have grown based on people's desires and capabilities. In an organic not so predefined way. So our development is more a journey, more than a schedule."

A sense of creativity (6) was also seen as an important factor defining the culture of Design Factory, facilitated by norms facilitating craziness (4), experimenting (3), and trusting (1). The space was often (10) mentioned as a way to support this.

"Cozy creative [...] space has a nice size and setup. Does not look perfect, which is a good thing. It is not too big given we are in a ramp-up phase. It encourages to prototype, but also just be there and enjoy."

Additionally, many shared student-oriented attitudes (6) as defining their Design Factory, e.g. by calling their freedom, development or experiences the ultimate goal. This was supported by various ways of learning and sharing (12 existing, 3 planned). Additionally, some things were done to keep students and other users engaged (2). Mostly this was explicated through various methods or programs offered to students (6), by facilitating exchanges (2) and by keeping communication open (1).

"Students in Design Factory learn methods to be innovative in every workspace. [...] While working on projects, the students write a PDP [Personal Development Plan]. This tracks their development and learning outcomes reflecting on knowledge, skills and attitude."

Fewer Design Factory representatives felt their passionate (2), innovative (2) and flexible (2) nature were most particular in describing their work environment, underlined by expressions of work being more than a job (2), despite it being exhausting (1). These norms were manifested in team building or training (2), and in diversity in personalities and allocation (2). 
"I'm super passionate about what I do at [...] Design Factory, for me this is more than a job, is more about enjoying what I do and always learning from others."

The existing attitude of being sustainable (1), or a future plan to be resilient (1) were not reflected in any norms or manifestations. Also a planned manifestation of getting more high-tech demos (1) such as AR or VR could not be linked to any attitude or norm, present or existing.

\subsection{Host organization}

In relation to the host organization a clear distinction could be seen in the stories put forth. The first one was about being different and autonomous, mostly in terms of values (mentioned 7 times in the stories), supported by a few norms (mentioned 3 times) and some manifestations (4). The second one was more about being part of the university, welcoming people in and spreading the culture. Fewer values (6) were connected to this theme, yet many more norms (25) and manifestations (31).

As stated, most attitudes shared were about being different (5), both expressed in positive and negative ways, as it meant they had to be willing to fight for many things. In line with this, they also expressed valuing remaining autonomous (2). Norms they shared therefore also sometimes included elements of comparison (3), as they enjoyed disrupting the status quo or providing space for people who are different. This manifested in clear detachment from the university (1), but also in moments of being unsupported (3) by the host or having ideas for spaces or courses being copied by other departments (2).

"There is so much tacit knowledge in behaviour and mindset we often seem like a bit of a mystery as to what exactly are we and how we do things. Also we have a big collection of different and special personalities. The culture gives more space for this to exist than in other areas of the organization."

Other attitudes were more about being part of the host, be it to spread the Design Factory spirit (2) or to welcome the university community into the Design Factory (4). Collaborating with or integrating existing university activities into the Design Factory (9), as well as always being open to all students and helping everybody (6), are norms contributing to achieving these values. Additionally, different norms of spreading the culture were mentioned, present ones (3) included inspiring all university students or seeing other university bodies being curious, whereas future plans (5) included influencing university staff and raising awareness at higher levels in the university. Many manifestations were mentioned to achieve being part of the host, such as running existing modules ( 5 present, 3 planned), expanding to more departments ( 2 present, 2 planned), and collaborating to run more activities together (4). Also the Design Factory representatives mentioned many instances of reaching out, both formally by doing creative facilitation (4) and informally with for example a shared breakfast (3), aided by an open door policy (3). Few manifestations (2) were meant to receive support and validation from the host.

"We are experimenting with how to get students and other departments get to know our place." "[We want] to be in other people's minds inside university as an opportunity space."

\subsection{Design Factory Global Network}

Least excerpts were related to the Design Factory Global Network, and of the ones that were, many came from future plans (mentioned 14 times in the stories), compared to descriptions of the present (mentioned 9 times).

Of the four mentioned attitudes related to the network, two were about enjoying it in general and two about learning from each other. As present norms, mostly exchanging students was mentioned (2), as well as learning best practices (1) and comparing to others (1). Representatives mostly shared future norms, expressing a wish to collaborate more by developing international projects (6), and sharing more throughout the year (2). As manifestations representatives mentioned an event mixing students from different design factories (1), and a comparison about their lack of a physical space (1). Wished manifestations for the future included more collaborations (3), more exchange of methods (1) and more design factories (1).

"Since we are recent in the network, there is still a lot of things to learn and to do. So I think in general we are curious about best practices and how can we grow." 
"I would love to continue in this network and be part of some program, coordinate it, or even design a new one. Also I would love to so to other DFs to make an impact and learn from other amazing people."

\subsection{Wider environment}

Attitudes towards the environment outside the Design Factory and the host were mentioned on two levels: a broad, societal impact (mentioned 8 times in the stories), and the work field (mentioned 8 times). Norms (17) and manifestations (14), however, only were related to the work field.

Attitudes targeting a broad, societal impact, often mention a sustainable future (5), or positive impact or influence in general (3). As said before, no norms or manifestations were mentioned to support these values.

"From an ecosystem perspective, DF has an influential role to its surroundings e.g. startups, companies, the city - perhaps the world as well!"

Additionally, representatives mentioned the importance of being understood (3), having success in the industry (3) and collaborating with the ecosystem (2). Many norms supported these intentions, mostly by emphasizing collaborating with industry in projects or to develop modules (8), but also by reaching out with workshops (5), inviting partners to events (2), or receiving validation (1) and attempting to be a real world simulator (1). Most mentioned manifestations are existing courses or cooperations with partners (7), followed by outreach activities such as workshops (3), and events to which partners are invited (3). Once a strategy document was mentioned including plans on both a local and global level.

"Our students stand out on job interviews because of the experience they have had working with international teams, communication, learning on our feet, conflict resolution, business plans etc. One of our students [...] who did PDP [Product Development Project] got hired as a an intern for one of the top public relations companies because PDP set her apart from all the other candidates."

\section{DISCUSSION}

Through a case study of a network of 24 knowledge hubs within universities and research institutions, we focused on aspects of culture, namely attitudes, norms, as well as concrete manifestations. In the sub-sections below we draw implications on each of the identified stakeholder relationships.

\subsection{Internal}

Most mentioned in stories describing the Design Factory targeting the internal community were related to inclusivity and adaptability, on all levels of culture, to welcome strangers and always being ready for unexpected situations, in line with Gryszkiewicz and Friederici (2014), who, through discussions with several researchers, identified "fluidity and diversity" as the first "fundamental hypothetical parameter" of an innovation hub, as, according to their study, it supports people who usually do not run into each other to connect and start working together. For organizations to be creative, high autonomy is required (e.g. Amabile, 1988, 2004; Auger \& Woodman, 2016), as was reflected by Design Factory representatives mentioning passion and being user-centered as core to their innovation hub, which translates to anyone inside the community, be it staff or student, to be able to act autonomously, to learn based on intrinsic motivation.

The role of space was also highlighted in many stories and examples. The ambiguous and intangible nature of change and innovation may contribute to the space being considered as a useful asset embodying the intangible characteristics of innovation. It aids communication and provides a focal point for external stakeholders to visit and experience innovation activities. This confirms Memon et al.'s (2018) work and strengthens the importance of physical space as a change agent and communication tool.

\subsection{Host organization}

The majority of stories describing a relationship with the host had negative connotations revealing tensions in practices, processes and values. Many expressed they have created a community, in which innovation can manifest more easily than at other locations of the host. Within the innovation hub a shared creative, inspired worldview emanates but this faces restrictions from the institution, which is 
more industrial and wants its entities to follow the rules of the game in order to control and guarantee quality (Meynhardt et al., 2016). As institutions have power in either enabling or restraining cocreation practices, and they often have insufficient understanding of how innovation catalysts operate, flourish or can prove their success (Toivonen, 2015), this often led to frustration in members of the DFGN.

Many issues seemed to originate from the innovation hub's aim to be different and ground-breaking, while, simultaneously, being dependent on the host in terms of receiving students, financial support, and legitimacy for educational activities; standing in the way of its wish to be autonomous. Thus, although values revolve around deviating or even challenging existing norms within the host (and surrounding society), norms and manifestations were often found to be aligned with what the traditional institution requires, to receive validation and legitimization. Innovation hubs need to conform by learning and using the language of their host in order to be understood (Liu \& Hinds, 2012), as some participants confirmed through their future plans (e.g. constructing bases for allocating credits, making clear strategies and action plans, as well as hosting training sessions about the Design Factory ways of working internally).

\subsection{Design Factory Global Network}

Nambisan and Baron (2013) suggested the survival of members of an ecosystem is closely linked to their co-dependency and common objectives, knowledge and skills. Similarly, the DFGN network is often described as a place to gain and share knowledge, best practices and tools with other members, aligned with how knowledge innovation hubs operate. Due to the cultural gap within their own host organization, some Design Factories mentioned the network as being a group that they could identify with and get support for their struggles, as well as enhancing their credibility as an educational entity so different from the host's way of providing education.

Very few stories however targeted the relationship with the network, suggesting Design Factories are more concerned with their own practice and fitting in their local institution. Many new Design Factories expressed wishes and future plans to collaborate more, whereas few present values, norms or manifestations of new or established Design Factories reflected this. Often comparisons were made by young Design Factories in a defensive way, for example by apologizing for not having a space as big as one of the more established Design Factories, revealing the struggle of working together with Design Factories of different maturity. Established Design Factories seemed to be less concerned with the collaboration, and wished for more general growth or local advancement. It may be that the established Design Factories have become tired of having to deal with forces from both their host and the network, as they are often conflicting, as Nambisan and Baron (2013) also found as a special challenge in various ecosystems.

\subsection{Wider environment}

Similar to the relationship with the host, when looking at the relationship with the wider environment values are generally very idealistic, reflecting societal impact in terms of creating a better, often sustainable, world. Manifestations on the other hand are more conforming to what is demanded, or expected, being seen mostly in industry collaborations and good career prospects. It reveals a struggle to be taken seriously in a society they wish to challenge with their own, deviating, world view.

\section{CONCLUSIONS}

Innovation platforms, knowledge hubs and other entities for driving innovation have gained traction amongst scholars, however strong understanding of the creation and functionality of such platforms remains unclear. Thus, the aim of this paper was to contribute to current conversations of global networks of knowledge hubs by collecting stories and generating insights into aspects of perceived culture in their activities and processes. This was done in a single case study using a survey and through specific settings, being innovation platforms housed by tertiary education institutions and research organisations. Our results contribute to the conversation of the attitudes, norms and practical manifestations of these types of locations, as well as practical implications of these on a systemic level and how cultures form through various social processes. 
Primary mandate and emphasis of these knowledge hubs seem to be the creation of an open, fluid and adaptive environment where everybody is welcome and autonomous. This is driven by a strong intrinsic motivation and values connected to a desired future state of the society. A physical space and even small explicit visual cues in the space play a major role in translating intangible values and strengthen the communication to actors outside of the hub. Despite being connected to a host institution a clear tension was present in the relationship between the hub and the organisation. This struggle is almost inevitable considering that knowledge hubs are often created to drive innovation and the present desire for being different, therefore having differing activities and processes. KoskelaHuotari et al. (2016) have well described that, in the context of service ecosystems, in order to successfully innovate "for new practices to become adopted, old practices need to be maintained to make the new practices more recognisable". People involved need to feel comfortable "while being challenged and invited to a new experience" (ibid).

Additionally, all hubs belong to one large, global network, intended to support, inspire and exchange experiences and learnings. It is mostly the younger hubs that express wishes for more collaboration, they compare themselves to more established hubs in aspirational ways, often apologetic, as they wish to acquire the same resources or status. Finally, often societal values are very idealistic, whereas norms and manifestations are more conforming to what is expected from the industry in terms of employability or marketability. It is the knowledge hub's opportunity to develop capability in tailoring the communication to have strong aspirational values and bring them back to incremental development steps for closely related stakeholders.

Authors acknowledge some limitations to this research. The study focused on one particular case study and looked at the phenomenon through specific settings, hence authors are reluctant to draw strong generalisations beyond the case and settings. In addition, the participants were limited to the specific group of people who are closely related to the innovation platform activities and their roles were not specified. Finally, not all representatives from all institutions in the network were reached. Thus, to address these limitations, authors suggest a few directions for further research. It would be fruitful to extend the data collection across multiple case studies from other sectors e.g. large private corporations to better understand whether the type of organisation has an effect on the way innovation platforms act. Furthermore, gathering more specific point of views from each role within the innovation platform e.g. staff, students and industry would be of interest. Finally, the tension between the innovation platform and the host organisation became clearly evident from the research, hence authors suggest further inquiry to extend the understanding of functionality of innovation platforms from the host organisation perspective and therefore contribute to the knowledge on creating innovative change in organisations.

\section{REFERENCES}

Aldrich, H.E. and Ruef, M. (2006), Organizations evolving (2nd ed.). Sage, Thousand Oaks, CA. https://doi.org/10.4135/9781446212509

Amabile, T.M. (1988), "A model of creativity and innovation in organizations”, Research in organizational behavior, Vol. 10 No. 1, pp. 123-167.

Amabile, T.M., Schatzel, E.A., Moneta, G.B. and Kramer, S.J. (2004), "Leader behaviors and the work environment for creativity: Perceived leader support”, The Leadership Quarterly, Vol. 15 No. 1, pp. 5-32. https://doi.org/10.1016/j.leaqua.2003.12.003

Auger, P. and Woodman, R.W. (2016), "Creativity and intrinsic motivation: Exploring a complex relationship", The Journal of Applied Behavioral Science, Vol. 52 No. 3, pp. 342-366. https://doi.org/10.1177/0021886316656973

Brown, A.D., Stacey, P. and Nandhakumar, J. (2008), "Making sense of sensemaking narratives", Human Relations, Vol. 61 No. 8, pp. 1035-1062. https://doi.org/10.1177/0018726708094858. https://doi.org/10.1177/0018726708094858

Clarysse, B., Wright, M., Bruneel, J., Mahajan, A. (2014), “Creating value in ecosystems: crossing the chasm between knowledge and business ecosystems", Res. Policy, Vol. 43 No. 7, 1164-1176. https://doi.org/10.1016/j.respol.2014.04.014

Eisenhardt, K.M. (1989), "Building theories from case study research", Academy of management review, Vol. 14 No. 4, pp. 532-550. https://doi.org/10.4135/9781412986274.n1

Eisenhart, K.M. and Graebner, M.E. (2007), "Theory building from cases: challenges and opportunities", Journal of Academy of Management, Vol. 50 No. 1, pp. 25-32. https://doi.org/10.5465/amj.2007.24160888 
Eriksson, P. and Kovalainen, A. (2015), "Qualitative Methods in Business Research: A Practical Guide to Social Research", Sage. https://doi.org/10.4135/9780857028044

Evers, H.D. (2008), "Knowledge hubs and knowledge clusters: designing a knowledge architecture for development", Working Paper Series 27, Department of Political and Cultural Change, Bonn.

Fiore A. and Rosani G. (2018), "Two questions to ask before you set up an innovation unit", Harvard Business Review, July 202018 https://hbr.org/2018/07/two-questions-to-ask-before-you-set-up-an-innovation-unit

Gryszkiewicz, L. and Friederici, N. (2014), "Learning from innovation hubs: fluidity, serendipity and community combined", Innovation Management. se. http://www.innovationmanagement.se/2014/12/15/learning-from-innovation-hubs-fluidity-serendipity-andcommunity-combined/

Koskela-Huotari, K., Siltaloppi, J. and Vargo, S.L. (2015), "Understanding institutional complexity in service ecosystems: insights from social network theory and systems thinking", In The 2015 Naples Forum on Service, 9-12, June, 2015, Naples, Italy. https://doi.org/10.1109/hicss.2016.202

Koskela-Huotari, K., Edvardsson, B., Jonas, J.M., Sörhammar, D. and Witell, L. (2016), “Innovation in service ecosystems-Breaking, making, and maintaining institutionalized rules of resource integration", Journal of Business Research, Vol. 69 No. 8, pp. 2964-2971.

Leminen, S., Westerlund, M. and Nyström, A.G. (2012), "Living Labs as open-innovation networks", https://doi.org/10.22215/timreview/602

Liu, L. and Hinds, P. (2012), "The Designer Identity, Identity Evolution, and Implications on Design Practice", In Design Thinking Research (pp. 185-196). Springer, Berlin. https://doi.org/10.1007/978-3-642-319914_10

Marshall, M.N. (1996), “Sampling for qualitative research”, Family practice, Vol. 13 No. 6, pp. $522-526$. https://doi.org/10.1093/fampra/13.6.522

Maykut, P. and Morehouse, R. (1994), "Beginning qualitative research: a philosophic and practical approach", Falmer, Bristol, PA.

Mattila P. and Turner C. (2017), "Transformation is not a game we can play alone: diversity is a key ingredient in thriving innovation ecosystems", Passion-Based Co-Creation, pp. 202-2013.

Memon, A.B., Meyer, K., Thieme, M. and Meyer, L.-P. (2018), "Inter-InnoLab collaboration: An investigation of the diversity and interconnection among Innovation Laboratories", Journal of Engineering and Technology Management, Vol. 47, pp. 1-21. https://doi.org/10.1016/j.jengtecman.2017.11.003

Schein, E.H. (1988), "Organizational culture" (Vol. 45, No. 2, p. 109). American Psychological Association.

Stake, R.E., 2005. "Qualitative case studies”, In: Denzin, N.K. and Lincoln, Y.S. eds., The Sage handbook of qualitative research, 3rd ed. Sage Publications, Thousand Oaks, pp. 443-466.

Toivonen, T. (2016), "What is the social innovation community? Conceptualizing an emergent collaborative organization", Journal of Social Entrepreneurship, Vol. 7 No. 1, pp. 49-73. https://doi.org/10.1080/19420676.2014.997779

Youtie J. and Shapira P. (2008), "Building an innovation hub: A case study of the transformation of university roles in regional technological and economic development," Research Policy, Vol. 37, No. 8, 2008, pp. 1188-1204, ISSN 0048-7333, https://doi.org/10.1016/j.respol.2008.04.012.

Wry, T., Lounsbury, M. and Glynn, M. (2011), "Legitimating Nascent Collective Identities: Coordinating Cultural Entrepreneurship”, Organization Science (Vol. 22). https://doi.org/10.1287/orsc.1100.0613

Yin, R.K. (2009), Case study research: design and methods, 4th ed. Sage Publications, Thousand Oaks, p. 219. 